\title{
PROJETO CARTOGRÁFICO E IMPLEMENTAÇÃO DE UM PROTÓTIPO DE ATLAS ESCOLAR INTERATIVO
}

\author{
Cartographic design and implementation of an interactive school atlas prototype \\ FERNANDA PUGA SANTOS \\ MÔNICA MODESTA SANTOS DECANINI \\ Programa de Pós-Graduação em Ciências Cartográficas \\ Universidade Estadual Paulista - UNESP/FCT \\ Rua Roberto Simonsen, 305 - Caixa Postal 468 \\ 19.060-900 - Presidente Prudente SP - Brasil \\ ferpuga@gmail.com; monca@fct.unesp.br
}

\begin{abstract}
RESUMO
Este trabalho tem por objetivo apresentar o desenvolvimento de um protótipo de Atlas Escolar Interativo para alunos do $4^{\circ}$ ciclo do ensino fundamental. A abordagem metodológica baseou-se na teoria de desenvolvimento cognitivo com a finalidade de produzir um material que possa ser compreendido e utilizado pelo público alvo. Para tanto, analisou-se as necessidades dos usuários com base nos Parâmetros Curriculares Nacionais relacionados à disciplina de Geografia e nos livros didáticos utilizados em algumas escolas do ensino fundamental. Além disso, aplicou-se recursos multimídia de animação e interatividade, de acordo com a teoria de comunicação cartográfica, para facilitar a leitura e compreensão de mapas e assim, o conhecimento dos fenômenos geográficos. O desenvolvimento do protótipo subdividiu-se em duas grandes etapas: projeto cartográfico e produção do Atlas. Para a implementação do Atlas utilizou-se os aplicativos Macromedia Flash MX, Visual Basic e a biblioteca MapObjects-ESRI. Embora o Atlas não tenha sido avaliado, vale ressaltar que foi projetado com base no conhecimento teóricometodológico do desenvolvimento cognitivo, e é importante que no futuro, esse produto seja testado com um grupo de alunos do referido ciclo para avaliar a real contribuição da animação e interatividade no ensino da Geografia.
\end{abstract}

Palavras-chave: Atlas Escolar; Cartografia Multimídia; Interatividade.

\section{ABSTRACT}

This paper aimed at developing an Interactive School Atlas prototype for students of elementary school. The methodology was based on the cognitive development 
theory, in order to make a product that can be understood and used by the students. Thus, it was analyzed the needs of the users mainly based on the National Curriculum and Geography books adopted in some elementary schools. Moreover, it was applied multimedia resources of animation and interactivity, were applied, according to the theory of cartographic communication, to facilitate the reading and understanding of maps. The development of the Atlas prototype was split into two stages: cartographic project and production. The Atlas was implemented by using the Macromedia Flash MX, Visual Basic and the library MapObjects-ESRI. Although the Atlas has not been evaluated yet, one should point out that it was designed according to the theoretical and methodological knowledge of the cognitive development. The generated product needs to be tested in the future so as to evaluate the actual contribution of the animation and interactive in the teaching of Geography.

Keywords: School Atlas; Multimedia cartography; Interactivity.

\section{INTRODUÇÃO}

$\mathrm{O}$ uso de mapas, Atlas e mais recentemente de imagens de sensoriamento remoto constitui uma importante parte do currículo escolar (BAULCH et al., 2005). De acordo com Bochicchio (1995) os Atlas Escolares são elaborados com base nos programas mínimos apresentados pelas autoridades educacionais e adequados ao nível do aluno. No ambiente ensino-aprendizagem de Geografia, os Atlas Escolares ganharam créditos entre os materiais didáticos e, atualmente, existe uma série de exemplares em formato impresso e digital, sendo estes, com conteúdo internacional, nacional, estadual, municipal e até mesmo local (MARTINELLI, 2009).

Estudos realizados por Liben et al. (2002) sugerem que a utilização de mapas contribui fortemente para o desenvolvimento dos conceitos de representação e espacialização, o que possibilita a compreensão da disposição das áreas e feições da Terra. Embora os mapas estejam presentes em diversas áreas do conhecimento humano, não são muito utilizados devido à complexidade de leitura (CASTNER,1987). Uma das grandes dificuldades dos alunos de ensino médio e fundamental das escolas públicas, apontada pelas provas de Exame Nacional do Ensino Médio - ENEM refere-se à interpretação de mapas (SILVA, 2009). Sendo assim, Atlas Escolares deveriam ser presença obrigatória em aulas de Geografia.

Para auxiliar o aprendizado de conceitos cartográficos, e facilitar o processo de interpretação dos mapas, os Parâmetros Curriculares Nacionais (PCNs) sugerem o emprego da tecnologia na educação por meio da utilização de recursos multimídia (BRASIL, 1998). Os recursos multimídia permitem a manipulação de representações cartográficas nos Atlas Digitais, o que possibilita a seleção e modificação de informações por meio de transformações de coordenadas, mudanças de pontos de vista e escala, generalização, entre outros, tornando-os mais motivadores e didáticos (CARTWRIGHT, 1999). 
Contudo, conforme alega Martinelli (2009), elaborar um Atlas Escolar não é uma tarefa simples. Para seu desenvolvimento, não basta apenas utilizar recursos multimídia, simplificar os mapas, selecionar os temas mais fáceis e a área geográfica a ser mapeada. Além de ponderar estes componentes é necessário considerar uma base teórica metodológica específica sobre a construção da noção de espaço e de representação por parte do aluno (MARTINELLI, 2009). A abordagem usualmente utilizada na área de ensino-aprendizagem é a teoria de organização do desenvolvimento intelectual de Piaget (PIAGET, 1967). No processo de leitura de mapas, existem ainda duas habilidades intelectuais que devem ser consideradas: as habilidades de acesso, que são habilidades básicas para a leitura de mapas, como por exemplo, dominar a sintaxe e convenções dos sistemas de símbolos; e as habilidades processuais, que são habilidades que utilizam os conhecimentos adquiridos pelas habilidades de acesso para extrair informações dos mapas e interpretar fenômenos geográficos e suas relações (CARSWELL e DE LEEUW, 1987).

Dentro deste contexto, o principal objetivo deste trabalho foi projetar e produzir um protótipo de Atlas Escolar Interativo (EDUCATLAS) para alunos do $4^{\circ}$ ciclo do ensino fundamental ( $7^{\mathrm{a}}$ e $8^{\mathrm{a}}$ séries), a fim de auxiliar o processo de aprendizagem no ensino de Geografia. Este projeto deu continuidade ao protótipo desenvolvido por Barros (2007), referente ao $3^{\circ}$ ciclo.

\section{DESENVOLVIMENTO DO PROTÓTIPO DO ATLAS ESCOLAR INTERATIVO}

O desenvolvimento do protótipo subdividiu-se em duas grandes etapas: projeto cartográfico e produção do Atlas. A etapa do projeto cartográfico consistiu na análise da demanda do usuário, especificação das variáveis interdependentes, e elaboração da interface visual do Atlas. Na fase de produção fez-se a aquisição e edição da base de dados geográficos e desenvolveu-se a interface do protótipo. Vale ressaltar que o projeto e produção de um Atlas não é um processo linear, pois há uma continua retro-alimentação entre as várias etapas (Figura 1).

\subsection{Projeto Cartográfico}

Para o desenvolvimento do projeto cartográfico adotou-se uma abordagem baseada em Keates (1989), Bos (1984) e Decanini e Imai (2000), a qual pode ser dividida em três fases principais: análise da demanda do usuário; especificação das variáveis interdependentes e elaboração do projeto da interface visual do Atlas.

\subsubsection{Análise da Demanda do Usuário}

A análise da demanda do usuário consistiu em um levantamento de informações e dados que atendem às necessidades do público alvo. Nesta etapa é fundamental verificar todos os fatores que fazem parte do processo de criação do produto, quais sejam: necessidades, nível de entendimento e percepção do usuário, meio de representação, circunstâncias de uso, complexidade da informação, possibilidades técnicas e custos (KOLACNY, 1977). 
Figura 1 - Etapas do projeto cartográfico e produção do Atlas Escolar. (Fonte: Adaptado de Barros e Decanini, 2008).

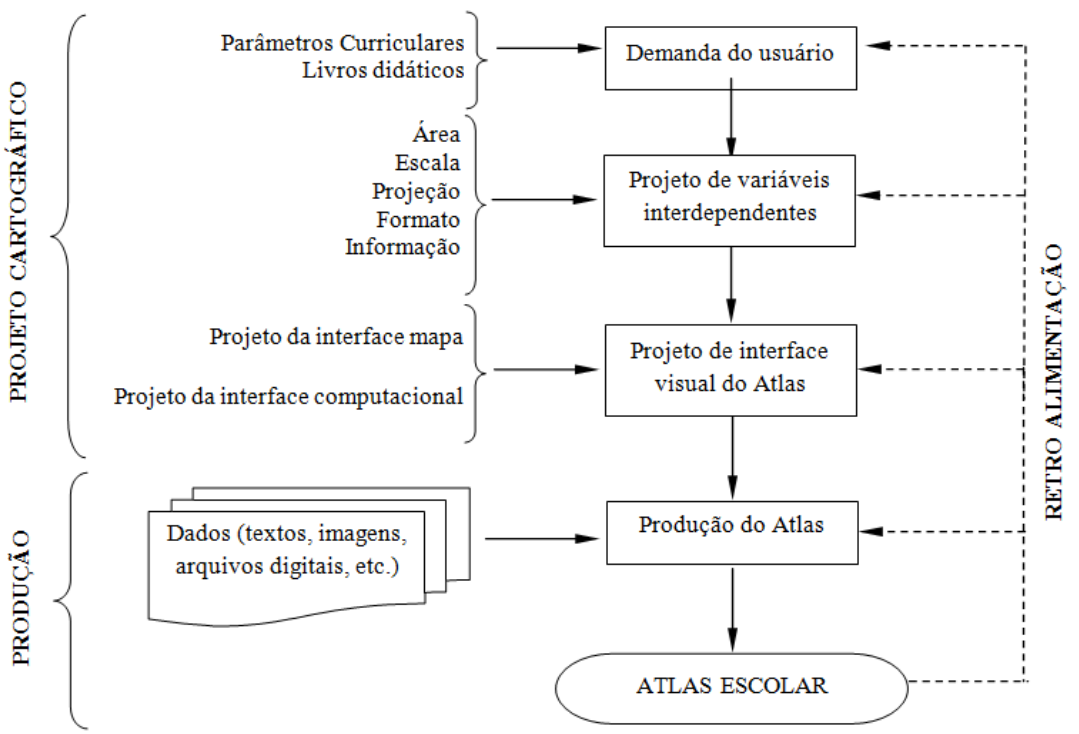

Apesar de considerar que o desenvolvimento da compreensão de informações espaciais acontece de forma exclusiva para cada indivíduo, Piaget (1967) delimita a capacidade de aprendizagem de novos conceitos em quatro estágios, com os quais descreve a possibilidade de aquisição e aperfeiçoamento das funções psíquicas. Esses estágios acontecem de forma linear, ou seja, não é possível chegar ao próximo nível sem que tenha adquirido os conceitos do nível anterior. A Tabela 1 resume as características de cada estágio.

De acordo com os estágios de desenvolvimento cognitivos apresentados na Tabela 1, a criança do $4^{\circ}$ ciclo fundamental se encontra na fase de pensamento formal. Com base nesta classificação, Passini (1995) afirma que o aluno neste estágio já possui condições para realizar análises e localizações, com correlação dos dados geográficos, e assim, pode ser considerado um leitor crítico de mapas. Ainda no contexto de desenvolvimento cognitivo, Carswell e De Leeuw (1987) consideram duas habilidades intelectuais para que um Atlas Escolar seja utilizado com eficiência no ensino de Geografia: as habilidades de acesso e as habilidades processuais. As habilidades de acesso são as habilidades básicas que os estudantes precisam incorporar para ler o mapa, enquanto as habilidades processuais são as habilidades de pensamento que permitem extrair informações e interpretar o fenômeno geográfico e suas relações. 
Tabela 1 - Descrição dos estágios do desenvolvimento cognitivo. Fonte: (Piaget, 1967).

\begin{tabular}{|c|c|c|}
\hline Estágio & $\begin{array}{l}\text { Faixa } \\
\text { etária }\end{array}$ & Características \\
\hline Sensório-motor & $0-2$ anos & Evolução da percepção e motricidade \\
\hline Pré-operatório & $2-7$ anos & $\begin{array}{l}\text { Interiorização dos esquemas de ação, } \\
\text { surgimento da linguagem do } \\
\text { simbolismo e da imitação deferida. }\end{array}$ \\
\hline $\begin{array}{l}\text { Operatório } \\
\text { Concreto }\end{array}$ & $7-11$ anos & $\begin{array}{l}\text { Construção e descentração cognitiva; } \\
\text { compreensão da reversibilidade sem } \\
\text { coordenação da mesma; classificação, } \\
\text { seriação e compensação simples }\end{array}$ \\
\hline $\begin{array}{c}\text { Operatório } \\
\text { Formal }\end{array}$ & $\begin{array}{c}\text { Acima de } \\
11 \text { anos }\end{array}$ & $\begin{array}{l}\text { Desenvolvimento das operações } \\
\text { lógicas matemáticas e infralógicas, da } \\
\text { compensação complexa (razão) e da } \\
\text { probabilidade (indução de leis) }\end{array}$ \\
\hline
\end{tabular}

Sendo assim, propôs-se para o $4^{\circ}$ ciclo algumas atividades que demandassem análise e interpretação de mapas conforme sugere Passini (1995), enquanto Barros (2007) focou principalmente nas atividades de alfabetização cartográfica por meio de exercícios de orientação geográfica, projeção, escala e compreensão dos signos, conforme proposto nos Parâmetros Curriculares Nacionais (BRASIL , 1998) para o $3^{\circ}$ ciclo.

A seleção do conteúdo do EDUCATLAS se deu em duas etapas quais sejam, estudo dos parâmetros curriculares nacionais e levantamento e análise de materiais didáticos. Primeiramente, para desenvolver o Atlas em módulos educacionais foi necessário conhecer as diretrizes propostas para cada ciclo de aprendizagem. Brasil (1998) subdivide o ensino fundamental em 4 ciclos: o primeiro contempla a $1^{\mathrm{a}}$ e $2^{\mathrm{a}}$ séries, o segundo a $3^{\mathrm{a}}$ e $4^{\mathrm{a}}$, o terceiro a $5^{\mathrm{a}}$ e $6^{\mathrm{a}}$, e o quarto ciclo a $7^{\mathrm{a}}$ e $8^{\mathrm{a}}$ séries. Portanto, realizou-se um estudo das diretrizes propostas para o $4^{\circ}$ ciclo, as quais norteiam tanto o ensino fundamental público quanto privado.

Em seguida realizou-se um levantamento de apostilas didáticas, referentes à sétima e oitava séries do ensino fundamental ( $4^{\circ}$ ciclo), das quais selecionou-se a do sistema Anglo de ensino (SCALZARETTO, 2007) e da rede Pitágoras (GAMA e BARBOSA, 2008), adotadas respectivamente pelo colégio Anglo e colégio Braga Mello de Presidente Prudente-SP. A escolha dessas apostilas ocorreu devido à facilidade de acesso ao material, o qual foi disponibilizado pelas escolas acima citadas. No caso das escolas públicas estaduais, o sistema de apostilas estava em fase de implantação no período de desenvolvimento desta pesquisa, desta forma, não foi possível ter acesso a este material. Entretanto, em contato com a Proposta Curricular do Estado se São Paulo (SÃO PAULO, 2008) pode-se constatar que as escolas públicas adotam, assim como as escolas privadas citadas, conteúdos 
propostos pelas diretrizes dos Parâmetros Curriculares, tais como Guerra Fria e Globalização. Além disso, o Atlas desenvolvido contém exercícios baseados em conteúdos de Atlas escolares nacionais como, por exemplo, o mapa de Recursos Minerais Brasileiros, o qual originalmente foi proposto de forma estática por Simielli (1988). Pode-se citar também, os exercícios de Problemática Ambiental e Globalização, os quais foram idealizados pelos próprios autores, considerando que se trata de um conteúdo proposto para a área de conhecimento de Geografia do $4^{\circ}$ ciclo do ensino fundamental, de acordo com Brasil (1998).

A partir da análise documental, com base nos Parâmetros Curriculares e no material didático coletado, selecionou-se os seguintes temas para o Atlas Escolar: Formas de Divisão do Mundo, Guerra Fria, Globalização, Recursos Minerais Brasileiros e Problemática Ambiental. Após a definição dos conteúdos, elaborou-se uma proposta metodológica (Tabela 2), a qual se associa os temas contemplados no Atlas às tarefas a serem realizadas e aos recursos de animação e interatividade. Adotou-se as variáveis dinâmicas momento no tempo, duração e ordem (MACEACHREN, 1995), além disso aplicou-se os recursos de animação esmaescimento e cintilação (PETERSON, 1999). Quanto aos recursos de interatividade utilizou-se os seguintes tipos classificados por Crampton (2002): toggling, consulta à base de dados, zoom in e zoom out, mudança de símbolo e filtragem. Enfatiza-se que as tarefas foram projetadas com o objetivo de trabalhar as habilidades processuais dos alunos.

\subsubsection{Especificação das Variáveis Interdependentes}

As variáveis interdependentes (região geográfica, informação, projeção e escala, formato da apresentação dos dados) foram definidas no inicio do projeto, uma vez que é nesta etapa que se dá a organização da informação, na qual se definem as classes e suas características, tais como sua dimensão espacial (geometria), os níveis de medida e o nível de percepção requerido (informação principal - tema versus informação secundária - base cartográfica). Na Tabela 3 apresenta-se um exemplo da organização da informação a ser representada no Atlas Escolar proposto.

As regiões geográficas foram definidas a partir das tarefas propostas durante a análise da demanda do usuário. As escalas cartográficas foram determinadas com base na configuração da mídia utilizada (monitor de 15' polegadas com resolução de 800x600 pixels) e a área de exibição do mapa no Atlas. Escolheu-se esta resolução com o objetivo de padronizar o formato do referente ciclo, com o formato implementado por Barros (2007). Todavia, existe a intenção de posteriormente alterá-lo, uma vez que os monitores utilizados hoje nas escolas possuem formato widescreen. Além disso, ressalta-se que este trabalho se trata de um protótipo, o qual ainda será testado e, se necessário, modificado.

Quanto as projeções cartográficas selecionou-se as mais adequadas para cada uma das regiões geográficas, considerando-se alguns elementos essenciais, quais 
sejam: propriedades da projeção, padrões de deformação e centro de projeção (DENT, 1999). Na Tabela 4 apresentam-se as projeções escolhidas.

Tabela 2 - Proposta metodológica de tarefas do EDUCATLAS para o $4^{\circ}$ ciclo.

\begin{tabular}{|c|c|c|}
\hline Temas & Tarefas & Recursos \\
\hline $\begin{array}{l}\text { Formas de } \\
\text { divisão do } \\
\text { mundo }\end{array}$ & $\begin{array}{c}\text { Comparar as diferentes } \\
\text { classificações do mundo atual } \\
\text { como Nível de } \\
\text { Desenvolvimento, Nível } \\
\text { Tecnológico e Blocos } \\
\text { Regionais, além dos } \\
\text { indicadores de } \\
\text { desenvolvimento e de riqueza } \\
\text { de um mesmo país. } \\
\end{array}$ & $\begin{array}{c}\text { • Interação com a } \\
\text { representação dos } \\
\text { dados. (zoom in/ zoom } \\
\text { out) } \\
\text { • Interação com os } \\
\text { dados. (consulta à } \\
\text { base de dados) }\end{array}$ \\
\hline $\begin{array}{c}\text { Blocos } \\
\text { Ideológicos }\end{array}$ & $\begin{array}{l}\text { Analisar o padrão espaço- } \\
\text { temporal das Alianças } \\
\text { Militares, assim como os } \\
\text { limites políticos dos países da } \\
\text { Europa antes, durante e depois } \\
\text { da Guerra Fria. }\end{array}$ & $\begin{array}{l}\text { - Animação temporal } \\
\text { (momento do tempo, } \\
\text { duração, ordem) } \\
\text { • Interação com a } \\
\text { dimensão temporal. } \\
\text { (toggling) } \\
\end{array}$ \\
\hline Globalização & $\begin{array}{l}\text { Localizar e identificar } \\
\text { elementos da globalização em } \\
\text { escala local. (cidade) }\end{array}$ & $\begin{array}{c}\text { • Interação com a } \\
\text { representação dos } \\
\text { dados (mudança de } \\
\text { símbolo) }\end{array}$ \\
\hline $\begin{array}{l}\text { Recursos } \\
\text { Minerais } \\
\text { Brasileiros }\end{array}$ & $\begin{array}{l}\text { Identificar, localizar e fazer } \\
\text { análise de padrões no mapa de } \\
\text { minerais existentes no Brasil. }\end{array}$ & $\begin{array}{l}\text { • Animação não } \\
\text { temporal } \\
\text { (esmaecimento e } \\
\text { cintilação) } \\
\text { - Interação com os } \\
\text { dados. (filtragem) } \\
\end{array}$ \\
\hline $\begin{array}{l}\text { Problemática } \\
\text { Ambiental }\end{array}$ & $\begin{array}{c}\text { Identificar o uso atual na área } \\
\text { de preservação permanente e a } \\
\text { área de mata remanescente a } \\
\text { nível local. }\end{array}$ & $\begin{array}{l}\text { - Interação com os } \\
\text { dados. (filtragem) }\end{array}$ \\
\hline
\end{tabular}

2.1.3 Projeto da interface visual do Atlas

O projeto da Interface visual do EDUCATLAS foi dividido em dois subprojetos: projeto da interface mapa, que consiste no projeto de componentes do mapa, o qual contém os elementos referentes aos mapas (símbolos, legenda, toponímia, reticulado, título); e o projeto da interface computacional, que é o projeto referente aos elementos que não estão inseridos nos mapas (cores da interface, 
botões de acesso, fonte dos textos referentes as atividades e layout). Todavia, foi realizada uma implementação piloto para testar as idéias preliminares do projeto de símbolos dos mapas, bem como o projeto dos botões de acesso. Dent (1990) aponta que o estágio de desenvolvimento de um modelo piloto auxilia no aprimoramento do projeto.

Tabela 3 - Exemplo da organização da informação geográfica.

\begin{tabular}{|c|c|c|c|c|}
\hline $\begin{array}{c}\text { Região } \\
\text { Geográfica }\end{array}$ & Tema & Domínio & $\begin{array}{c}\text { Dimensão } \\
\text { Espacial }\end{array}$ & $\begin{array}{c}\text { Nível de } \\
\text { medida }\end{array}$ \\
\hline $\begin{array}{c}\text { Cidade } \\
\text { (Presidente } \\
\text { Prudente) }\end{array}$ & Serviço & $\begin{array}{l}\text { Banco HSBC; Mc } \\
\text { Donald`s, Carrefour; } \\
\text { Michelin; Delícias do } \\
\text { Cerrado; Banco do } \\
\text { Brasil, Volkswagen; } \\
\text { Santander Banespa }\end{array}$ & Ponto & qualitativo \\
\hline $\begin{array}{c}\text { Continente } \\
\text { (Europa) }\end{array}$ & $\begin{array}{c}\text { Aliança } \\
\text { Militar }\end{array}$ & $\begin{array}{l}\text { - Países do Pacto de } \\
\text { Varsóvia } \\
\text { - Países da Otan } \\
\text { - Países socialistas } \\
\text { sem aliança } \\
\text { - Países capitalistas } \\
\text { sem aliança }\end{array}$ & Área & qualitativo \\
\hline
\end{tabular}

Tabela 4 - Sistema de projeção para as regiões geográficas.

\begin{tabular}{c|c|c}
\hline Região Geográfica & Escala & Projeção \\
\hline Mundo (Países) & $(1: 200.000 .000)$ & Robinson \\
\hline Continente (Europa) & $(1: 28.000 .000)$ & $\begin{array}{c}\text { Albers com dois paralelos } \\
\text { padrão }\end{array}$ \\
\hline País (Brasil) & $(1: 35.000 .000)$ & Policônica \\
\hline Cidade (Prudente) & $(1: 25.000)$ & $\begin{array}{c}\text { Cilíndrica Transversa de } \\
\text { Mercator }\end{array}$ \\
\hline $\begin{array}{c}\text { Cidade (Álvares } \\
\text { Machado) }\end{array}$ & $(1: 25.000)$ & $\begin{array}{c}\text { Cilíndrica Transversa de } \\
\text { Mercator }\end{array}$ \\
\hline
\end{tabular}

\subsubsection{Projeto da interface mapa}

O projeto de símbolos cartográficos é considerado uma das etapas mais importantes no processo de comunicação cartográfica. A simbologia dos mapas do EDUCATLAS foi estabelecida de forma que as propriedades visuais dos símbolos representassem as características e níveis de medida do fenômeno geográfico, conforme a teoria da comunicação monossêmica (BERTIN, 1983, BOS, 1984). 
Dentro deste contexto, apresenta-se na Tabela 5 o projeto de símbolos elaborado para o mapa de Recursos Minerais Brasileiros.

Tabela 5 - Projeto de símbolos para o mapa de Recursos Minerais Brasileiros.

\begin{tabular}{c|c|c}
\hline Domínio & Cor $(\mathrm{R}, \mathrm{G}, \mathrm{B})$ & Símbolo \\
\hline Divisão Regional & $(255,000,000)$ & \\
\hline Divisão Estadual & $(000,000,000)$ & \\
\hline Minerais metálicos & $(000,255,000)$ & (Interativo) \\
\hline Minerais não metálicos & $(000,000,255)$ & $\square$ (Interativo) \\
\hline Minerais energéticos & $(255,000,000)$ & $\Delta$ (Interativo) \\
\hline
\end{tabular}

No projeto de símbolos original deste mapa, proposto por Simielli (1988), as classes de minerais são separadas pela variável visual forma (ć́rculo para minerais metálicos, quadrado para minerais não metálicos, e triângulo para minerais energéticos) e a distinção das subclasses é realizada pela variável visual matiz da cor (Figura 2 - a). Sendo assim, este projeto apresenta uma solução exaustiva, conforme classifica Martinelli (1991). No entanto, para o EDUCATLAS foi proposto um novo projeto, o qual diferencia as classes de minerais pela variável visual matiz da cor (Figura 2 - b) e as subclasses pelo recurso de animação esmaecimento.

Figura 2 - Alteração do projeto de símbolos cartográficos para o mapa de Recursos Minerais Brasileiros.

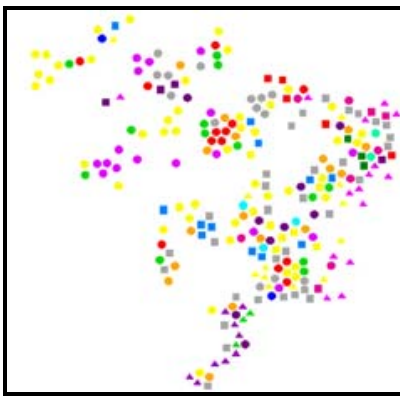

a) Projeto apresentado por SIMIELLI (1998)

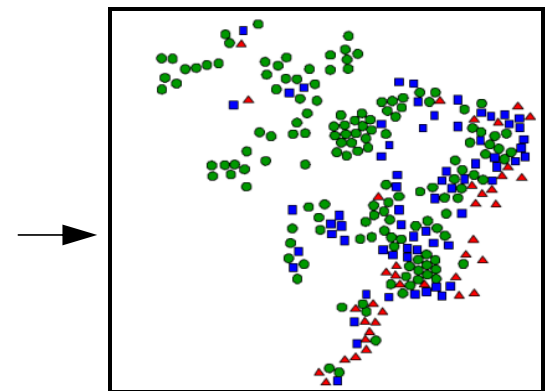

b) Projeto proposto para o EDUCATLAS

A separação por matiz da cor das classes possibilita ao leitor agrupar instantaneamente os tipos de minerais mais generalizados, o que pode favorecer a leitura de padrões espaciais, uma vez que a variável visual matiz da cor é seletiva, diferentemente da variável forma que é somente associativa (BERTIN, 1983; BOS, 1984). Além disso, os recursos de interatividade filtragem (Figura 3) e de animação 
esmaecimento e cintilação (Figura 13) permitem a criação de uma coleção de mapas para cada classe e subclasse, respectivamente.

Figura 3 - Recurso de interatividade filtragem do mapa Recursos Minerais Brasileiros.
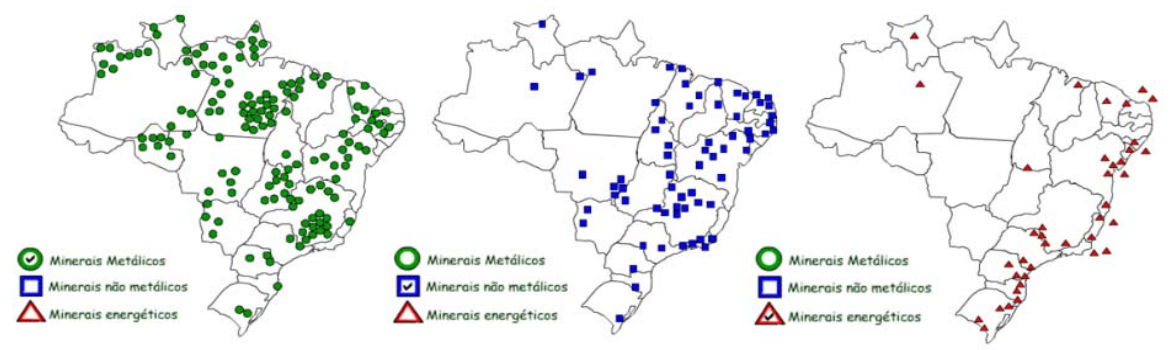

Na Tabela 6 apresenta-se o projeto de símbolos criado para o mapa de Alianças Militares do Pós-Guerra.

Tabela 6 - Projeto de símbolos para o mapa de Alianças Militares do Pós-Guerra.

\begin{tabular}{l|c|c}
\multicolumn{1}{c|}{ Domínio } & Cor (R,G B) & Símbolo \\
\hline Países do Pacto de Varsóvia (socialistas) & $(255,151,151)$ & $\square$ \\
\hline Países da Otan (capitalistas) & $(139,206,000)$ & $\square$ \\
\hline Países socialistas sem aliança militar & $(255,217,217)$ & $\square$ \\
\hline Países capitalistas sem aliança militar & $(221,255,151)$ & $\square$ \\
\hline Oceano & $(223,242,255)$ & \\
\hline
\end{tabular}

A atividade original proposta pelos livros didáticos para o tema (GAMA e BARBOSA, 2008) consiste em analisar dois mapas estáticos para verificar as alterações que ocorreram no mapa político da Europa antes e depois da Guerra Fria. Para o EDUCATLAS, propôs-se uma animação temporal e interativa, a qual apresenta em uma linha do tempo todas as mudanças entre as Alianças Militares ocorridas ao longo dos anos. O projeto de símbolos consiste das variáveis estáticas valor da cor para diferenciar países com e sem aliança militar (cor escura e cor clara respectivamente) e matiz da cor para distinguir o tipo de economia entre os países (magenta para socialistas e verde capitalistas). Além disso, propôs-se o uso das variáveis dinâmicas momento no tempo (para representar a criação do muro de Berlim no ano de 1961), duração (variável utilizada para determinar o tempo que cada país fica com uma determina cor) e ordem (utilizada para sequenciar os quadros). Na Figura 4 apresenta-se uma sequência de três quadros referentes aos anos de 1949 (criação da Otan), 1961 (criação do muro de Berlim) e 1990 (fim da URSS), respectivamente. 
Figura 4 - Parte da animação temporal do mapa Alianças Militares do Pós-Guerra.
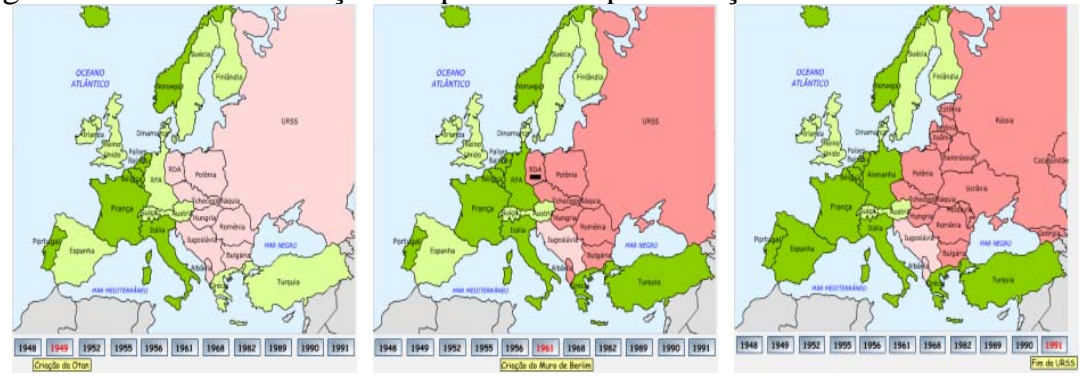

Na Tabela 7 apresenta-se o projeto de símbolos elaborado para o mapa de Globalização.

Tabela 7 - Projeto de símbolos para o mapa de Globalização.

\begin{tabular}{c|c|c}
\hline Domínio & Cor (R,G,B) & Símbolo \\
\hline Via & $(216,216,216)$ & $\bar{\square}$ \\
\hline Quadra & $(252,244,232)$ & \\
\hline Área de lazer & $(255,255,051)$ & \\
\hline Banco HSBC & - & (Interativo) \\
\hline MacDonald`s & - & (Interativo) \\
\hline Carrefour & - & (Interativo) \\
\hline Michelin & - & (Interativo) \\
\hline Delícias do Cerrado & - & (Interativo) \\
\hline Banco do Brasil & - & (Interativo) \\
\hline Volkswagen & - & (Interativo)
\end{tabular}

Esta tarefa foi desenvolvida, pois, de acordo com Scalzaretto (2007) a maioria dos estudantes possui dificuldade em compreender a forma com que a globalização está inserida em sua vida. Para tanto, propôs-se uma atividade com um mapa da Acidade de Presidente Prudente - SP. Neste mapa, inseriram-se alguns símbolos de empresas nacionais e internacionais. O projeto de símbolos proposto adotou o logotipo original das mesmas. Além disso, estes símbolos foram projetados com o recurso de interação mudança de símbolo Este recurso altera o tamanho do símbolo da empresa com o passar do ponteiro, além de exibir o nome da mesma (Figura 5). 
Figura 5 - Recurso de interatividade mudança de símbolo do mapa de Globalização.

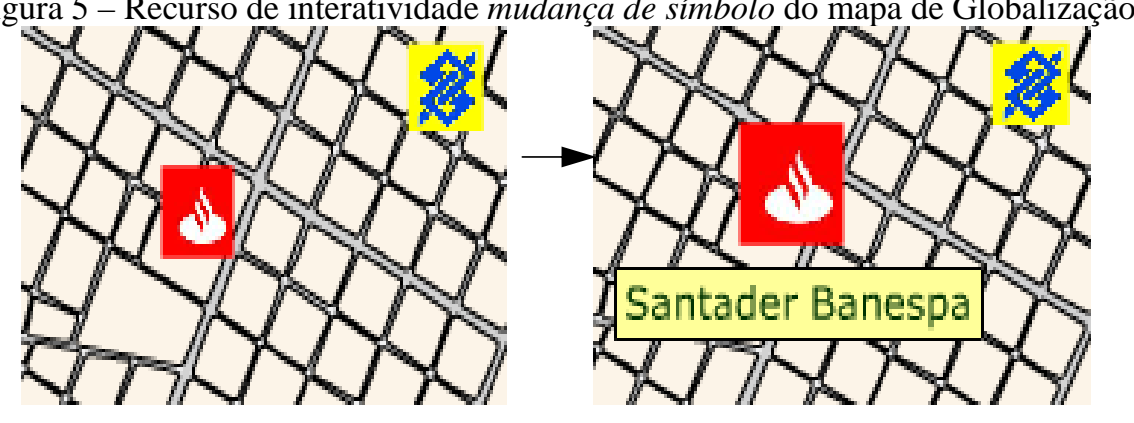

Na Tabela 8 apresenta-se o projeto de símbolos elaborado para o mapa de Problemática Ambiental.

Tabela 8 - Projeto de símbolos para o mapa de Problemática Ambiental.

\begin{tabular}{l|c|c}
\hline \multicolumn{1}{c|}{ Domínio } & Cor (R,G,B) & Símbolo \\
\hline Lotes & $(252,244,232)$ & $\square$ \\
\hline Área de preservação permanente & $(255,152,101)$ & \\
\hline Vias & $(216,216,216)$ & \\
\hline Curso d'água & $(000,000,255)$ & \\
\hline Nascente & $(000,000,255)$ & \\
\hline
\end{tabular}

Esta tarefa foi proposta conforme recomendação dos Parâmetros Curriculares Nacionais (BRASIL, 1998), para os quais é necessário produzir e organizar materiais didáticos que abordem a realidade local, além de problematizar eventos ou situações para discutir o comportamento social e suas relações com a natureza. Para tanto, elaborou-se uma atividade com o mapa da cidade de Álvares Machado - SP, com um símbolo interativo que representa a área de preservação permanente em torno dos cursos d’água e das nascentes. Este símbolo funciona por meio da ferramenta de interação com os dados filtragem. Esta tarefa está descrita no item 2.2.2.

Na Tabela 9 apresenta-se o projeto de símbolos elaborado para o mapa Formas de Divisão do Mundo. O projeto consiste nas tradicionais variáveis estáticas valor da cor, valor, matiz e valor da cor (para Nível de Desenvolvimento, IDH e PIB respectivamente. Os símbolos foram projetados de forma interativa por meio da ferramenta de interação filtragem. Esta ferramenta está descrita detalhadamente no item 2.2.1.

Para o projeto de toponímia adotou-se a fonte Verdana do Windows proposta por Barros (2007) para o EDUCATLAS - $3^{\circ}$ ciclo. Os produtos cartográficos resultantes são apresentados no item 2.2. 
Tabela 9 - Projeto de símbolos para o mapa Formas de Divisão do Mundo.

\begin{tabular}{|c|c|c|c|}
\hline \multicolumn{2}{|c|}{ Domínio } & Cor $(R, G, B)$ & $\begin{array}{c}\text { Símbolos } \\
\text { (interativos) }\end{array}$ \\
\hline \multirow{2}{*}{$\begin{array}{c}\text { Nível de } \\
\text { desenvolvimento }\end{array}$} & Desenvolvidos & $(031,168,030)$ & \\
\hline & Subdesenvolvidos & $(166,255,165)$ & \\
\hline \multirow{4}{*}{ IDH } & Alto $(0,8-1)$ & $(120,120,120)$ & \\
\hline & Médio $(0,5-0,799)$ & $(165,165,165)$ & \\
\hline & Baixo $(0-0,499)$ & $(210,210,210)$ & \\
\hline & Não disponível & $(255,255,255)$ & \\
\hline \multirow{5}{*}{$\begin{array}{l}\text { PIB em Bilhões } \\
\text { de dólares }\end{array}$} & Mais que 8000 & $(255,102,000)$ & \\
\hline & $4401-8000$ & $(255,204,000)$ & \\
\hline & $1201-4400$ & $(255,255,051)$ & \\
\hline & $300-1200$ & $(255,255,153)$ & \\
\hline & Menos que 300 & $(225,255,255)$ & \\
\hline
\end{tabular}

\subsubsection{Projeto da interface computacional}

Shneiderman (1998) indica que um dos princípios fundamentais para um bom projeto de interface é buscar a consistência nas cores. Com o intuito de manter a consistência nas cores e a padronização no EDUCATLAS, foi adotado o projeto de cores da interface utilizado por Barros (2007), com o predomínio de tons suaves de azul. Além disso, manteve-se o mesmo projeto de fontes padrão para os textos do Atlas: Comic Sans.

Com a finalidade de tornar a utilização do Atlas mais intuitiva, utilizou-se botões globais representados por símbolos metafóricos, os quais permitem ao usuário entender um elemento em termos de outro, familiar, sem sugerir que os dois são iguais (DELAZARI, 2004). Estes botões aparecem em mais de uma janela do EDUCATLAS com a mesma função (SANTOS E DECANINI, 2010), o que facilita a navegação.

O Layout dos mapas e textos foi projetado de forma a integrar a interface gráfica do EDUCATLAS - $3^{\circ}$ ciclo. Desta maneira, faz-se necessário utilizar a mesma configuração utilizada por Barros (2007), a qual consiste em uma área de 800x600 pixels, maiores detalhes estão descritos sucintamente em Barros e Decanini (2008).

A janela inicial do EDUCATLAS possui quatro botões de forma a permitir ao usuário (professor/aluno) escolher qual dos ciclos de aprendizagem deseja utilizar. Na Figura 6 o layout da janela inicial está apresentado com 30\% do tamanho original do Atlas. 
Figura 6 - Layout da janela inicial do EDUCATLAS.

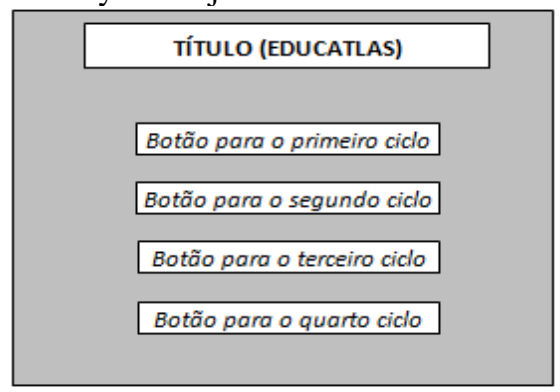

Foram definidos três layouts base para o $4^{\circ}$ ciclo, conforme padrão projetado por Barros (2007) para o $3^{\circ}$ ciclo: janela de apresentação dos temas (layout A), janela de apresentação dos textos (layout B) e janela de apresentação dos mapas (layout C) (Figura 7).

Figura 7 - Layout das janelas do EDUCATLAS.

(Fonte: Adaptado de Barros 2007).

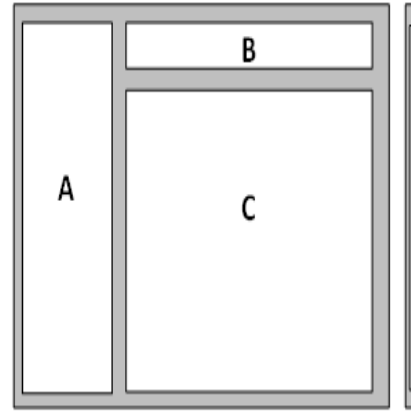

layout A

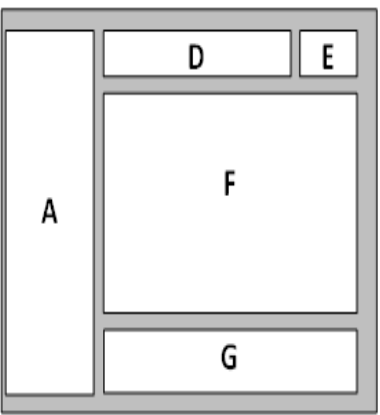

layout B

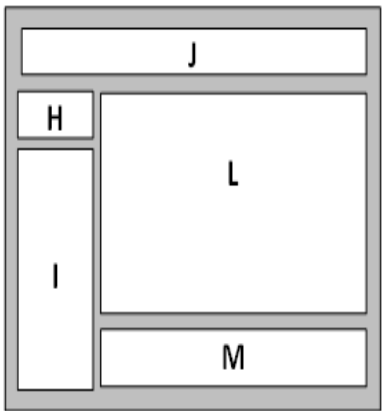

lavout $\mathrm{C}$

A - Botões de acesso para navegação no Atlas (Botões Globais)

B - Título referente à parte do Atlas (Mundo ou Brasil)

C - Área de exibição dos botões dos temas de cada parte do Atlas (Mundo ou Brasil)

D - Nome do Tema

E - Paginação (Interativa)

F - Área de exibição do texto referente ao tema

G - Área de exibição do glossário rápido

$\mathrm{H}$ - Ferramenta (interativa)

I - Legenda (Interativa e não interativa)

$\mathrm{J}$ - Título da tarefa ou do mapa

L - Área de exibição do mapa

$\mathrm{M}$ - Texto referente à tarefa a ser realizada

Bol. Ciênc. Geod., sec. Artigos, Curitiba, v. 17, nº 4, p.496-518, out-dez, 2011. 
A janela de apresentação dos temas (layout A) é constituída por botões de temas e botões globais. Os botões globais aparecem também na janela de apresentação de textos (layout B), a qual segue o estilo da janela de apresentação dos temas (layout A), todavia, o lado direito é dividido em área de apresentação do texto e área do glossário, além disso, no canto superior da janela encontram-se os botões referentes à paginação. Na janela de apresentação dos mapas (layout C) os componentes variam de acordo com as ferramentas utilizadas em cada tarefa. Em todas as janelas de apresentação de mapas e tarefas colocou-se o mapa no lado direito e a legenda em um espaço à esquerda. Escolheu-se esta disposição para priorizar o foco de atenção, pois, de acordo com Dent (1990), o olhar do observador segue um trajeto diagonal do canto superior esquerdo até o canto inferior direito. Sendo assim, posicionou-se os botões de acesso às atividades, bem como a legenda, que define a semântica do mapa, do lado esquerdo das janelas. Entretanto, esta disposição é uma proposta preliminar, que deverá ser testada posteriormente com a finalidade de verificar sua eficácia.

\subsection{Produção do Atlas: Resultados}

Foram criados três tipos de mapas EDUCATLAS - $4^{\circ}$ ciclo, quais sejam: estático "só para ver", estático interativo e animado interativo, conforme classificação de Brown et al. (2001). Os mapas estáticos foram criados em ArcView 3.2, os mapas animados e interativos foram criados em Macromedia Flash Mx e Visual Basic (VB).

As janelas do EDUCATLAS foram criadas em Macromedia Flash. Em seguida, estes arquivos foram integrados aos formulários (janelas) do Visual Basic. A integração é possibilitada por meio da inserção de um componente no VB, denominado Shockwave flash, o qual permite apresentar arquivos com extensão swf e atribuir a esses arquivos algumas funcionalidades já programadas do VB como, por exemplo, zoom e ferramentas de pesquisa.

O EDUCATLAS - $4^{\circ}$ ciclo não foi estruturado de forma linear, ou seja, os temas apresentados não devem ser compreendidos como uma sequência de assuntos, desta forma é de responsabilidade do professor orientar o aluno sobre qual botão da janela inicial acessar.

Em cada um dos botões para navegação no Atlas (Mundo e Brasil), há diversos temas. O botão Mundo disponibiliza os botões dos temas: Formas de Divisão do Mundo, Blocos Ideológicos e Blocos Econômicos. O botão Brasil disponibiliza os botões dos temas: Globalização, Recursos Minerais Brasileiros, e Problemática Ambiental. A Figura 8 apresenta as janelas Mundo e Brasil com seus respectivos botões de temas, cada uma com 30\% do tamanho original do Atlas. 
Figura 8 - EDUCATLAS - $4^{\circ}$ ciclo menu Mundo e Brasil.

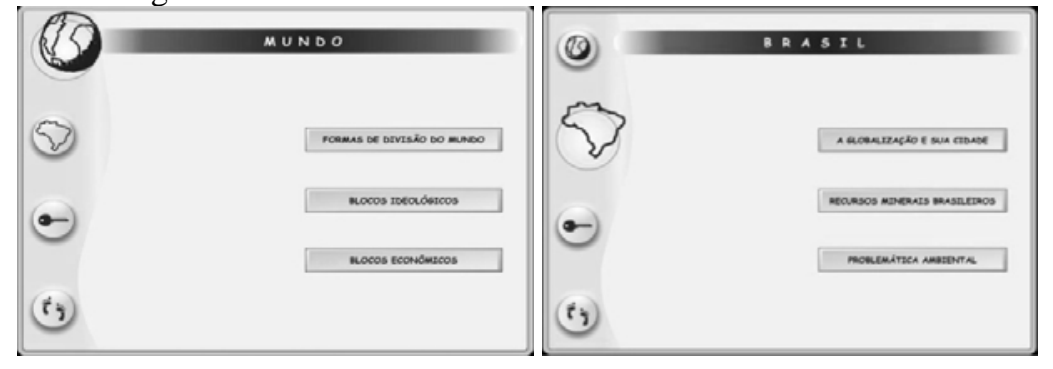

\subsubsection{Tarefas do Botão Mundo}

O botão Mundo dá acesso a uma janela com três botões de temas relacionados a assuntos mundiais, quais sejam: Formas de Divisão do Mundo, Blocos Ideológicos e Blocos Econômicos. A tarefa do tema Formas de Divisão do Mundo consiste em responder uma série de questões com o objetivo de comparar as diversas classificações dadas a um mesmo país, por meio de consulta de valores de IDH, PIB, Renda per capita e associar esses valores ao Nível de Desenvolvimento, Nível Tecnológico e ao Bloco Regional conforme Tabela 2. Por exemplo, na primeira questão pergunta-se o valor do PIB do Brasil. Para responder, o aluno tem que selecionar o campo da legenda interativa que contêm esse atributo. As questões subsequentes foram elaboradas com o mesmo objetivo (comparar as classificações), contudo, para respondê-las o aluno necessita utilizar outras ferramentas disponíveis no Atlas como zoom in/ zoom out e consulta à base de dados, por meio da ferramenta de informação (Figura 9).

Figura 9 - Tarefa do tema Formas de Divisão do Mundo.

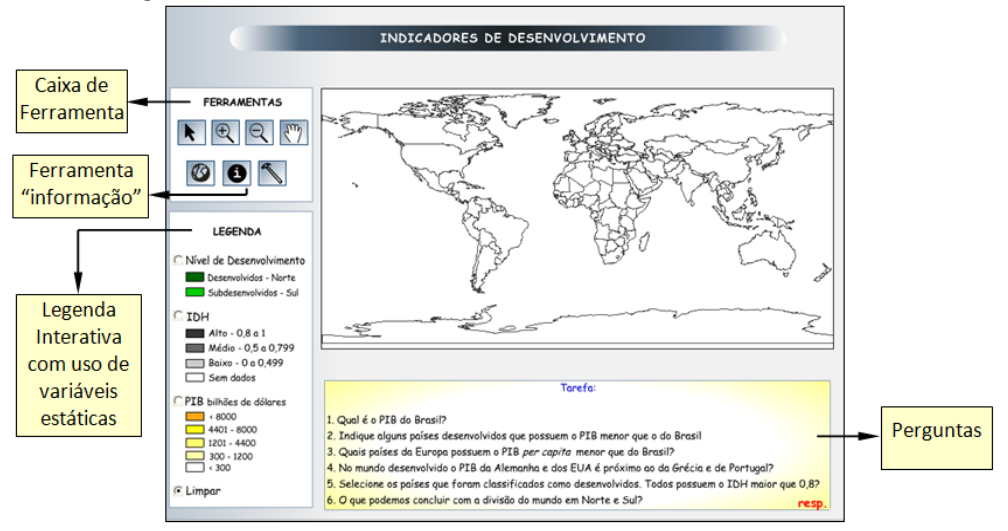

Bol. Ciênc. Geod., sec. Artigos, Curitiba, v. 17, nº 4, p.496-518, out-dez, 2011. 
Essas ferramentas podem facilitar o processo de interpretação do mapa, uma vez que são recursos que possibilitam a seleção de um tema de interesse e a ampliação da área de visualização no mapa.

A tarefa do tema Blocos Ideológicos consiste em analisar o padrão espaçotemporal das Alianças Militares, assim como os limites políticos dos países da Europa antes, durante e depois da Guerra Fria. Para tanto, elaborou-se uma animação temporal para representar a forma com que as Alianças Militares se expandiram durante o período da Guerra-Fria. O mapa apresenta as mudanças ocorridas nos grupos da OTAN e do Pacto de Varsóvia, no período de 1948 a 1991. A integração com a dimensão temporal se deu pela ferramenta interativa toggling, a qual permite iniciar e parar a animação em qualquer posição da linha do tempo (Figura 10).

Figura 10 - Animação temporal das Alianças Militares do Pós-Guerra.

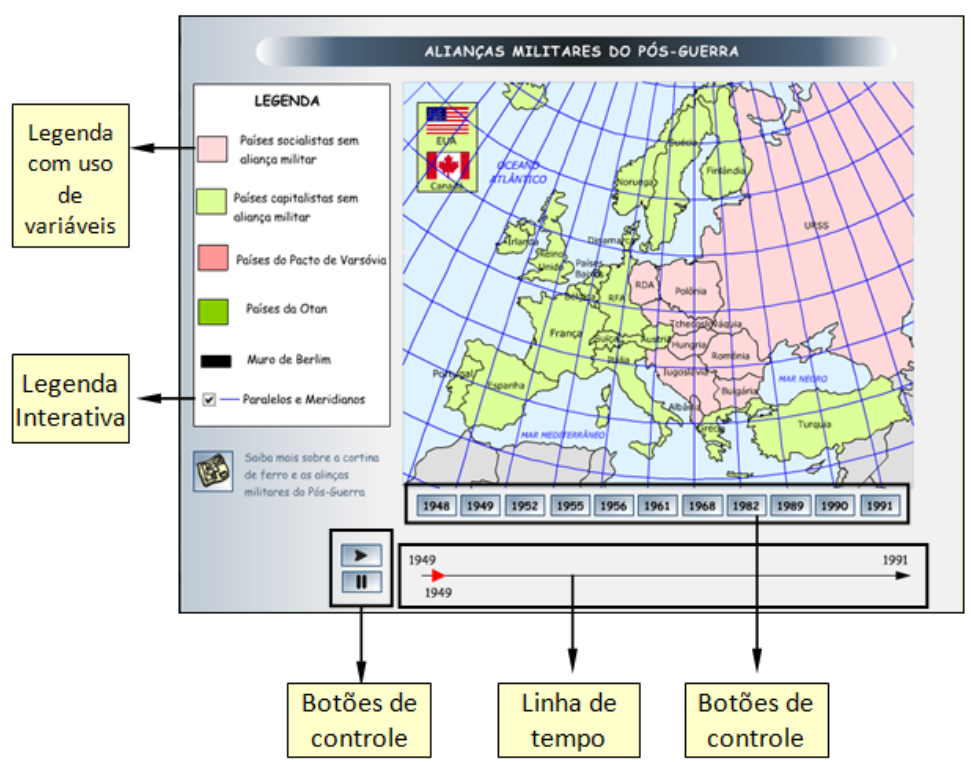

Isso permite tanto ver o padrão espaço-temporal do fenômeno geográfico quanto em um dado ponto no tempo.

\subsubsection{Tarefas do Botão Brasil}

Este botão dá acesso a uma janela com três botões de temas relacionados ao território brasileiro, quais sejam: Problemática ambiental, Globalização e Recursos Minerais Brasileiros. A tarefa do tema Globalização consiste em localizar e identificar elementos da globalização em escala local. Para tanto, em um mapa da 
cidade de Presidente Prudente o aluno tem que apontar os símbolos de empresas que indicam globalização. Os símbolos cartográficos no mapa funcionam como botões, os quais, caso a resposta do aluno esteja correta, apresentam uma janela parabenizando-o e mostrando informações como país de origem, ano de fundação e países de atuação. Caso contrário, a janela indica o erro e justifica com a informação correta (Figura 11).

Figura 11 - Janela de exercício sobre globalização.

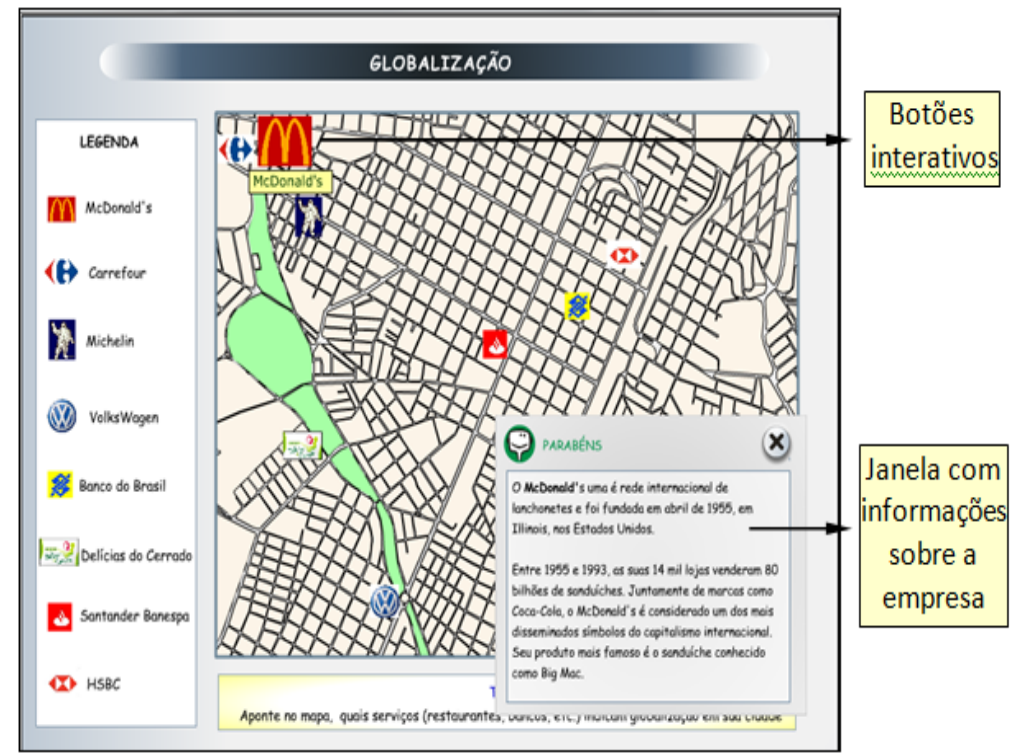

A tarefa do tema Problemática Ambiental consiste em identificar o uso atual na área de preservação permanente e a área de mata remanescente a nível local por meio da ferramenta de interação com os dados filtragem. Nesta tarefa o aluno é questionado sobre o tamanho das áreas de preservação permanente para os rios apresentados. Com o recurso de legenda interativa, pelo componente check box, selecionam-se as áreas de preservação permanente, o que possibilita a análise da situação ambiental na cidade em questão (Figura 12). 
Figura 12 - Janela de exercício sobre Problemática Ambiental.

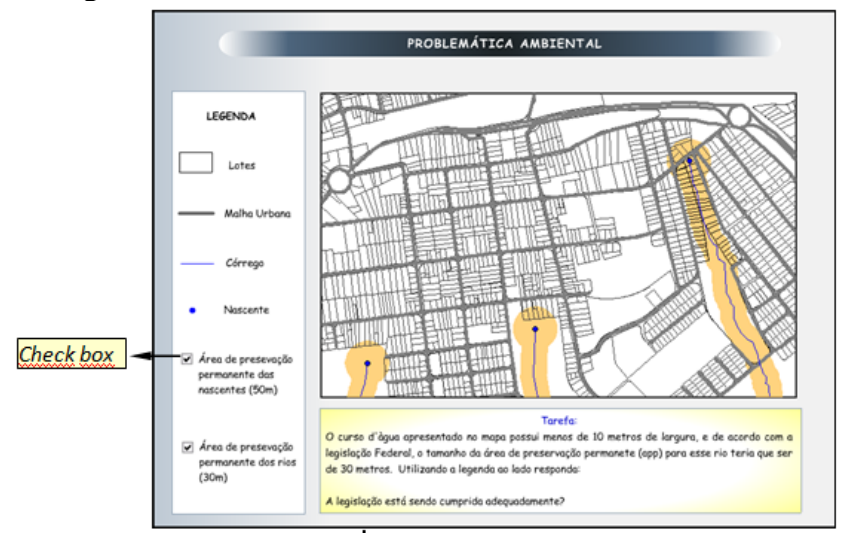

A tarefa do tema Recursos Minerais Brasileiros consiste em identificar, localizar e fazer análise de padrões no mapa de minerais do Brasil. Para tanto, disponibiliza-se recursos de animação não temporal como cintilação e esmaecimento, bem como recursos de interação com os dados por filtragem, conforme descrito no item 2.1.3.1 Utilizou-se a filtragem, por meio do componente check Box, para apresentar separadamente as classes de minerais (metálicos, não metálicos e energéticos). Os recursos de esmaecimento e cintilação foram adotados, respectivamente, para mostrar as subclasses em coleção de mapas e para enfatizar a localização de cada subclasse. Além disso, na medida em que o aluno explora o mapa aparecem janelas com textos explicativos referentes ao mineral selecionado (Figura 13).

Figura 13 - Janela de exercícios sobre Recursos Minerais Brasileiros

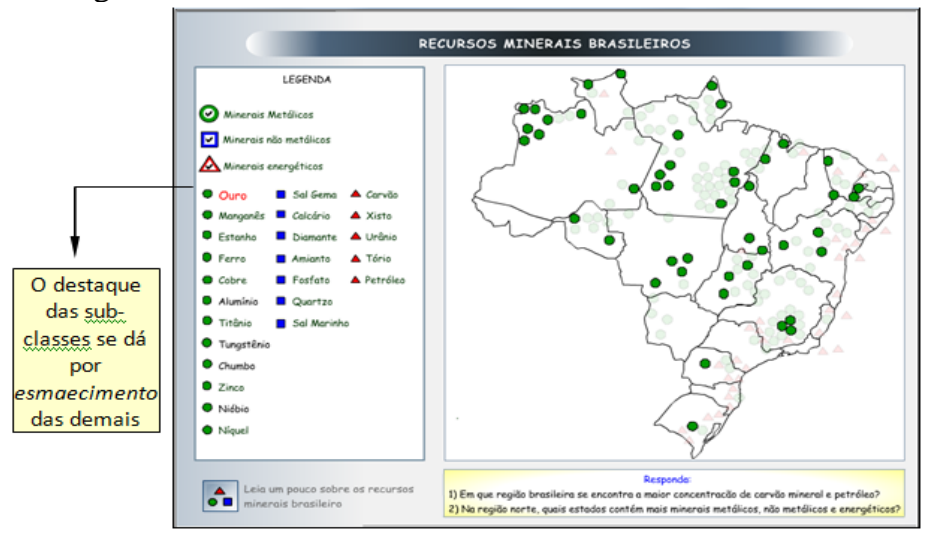

Bol. Ciênc. Geod., sec. Artigos, Curitiba, v. 17, nº 4, p.496-518, out-dez, 2011. 


\section{CONCLUSÕES E RECOMENDAÇÕES}

A criação de um Atlas Escolar é um processo que envolve muitas variáveis e a organização destas, por meio de um projeto cartográfico, é essencial para gerar um produto que se adeque efetivamente ao propósito e às demandas do usuário. Sendo assim, deve-se enfatizar que para elaborar um Atlas Escolar é fundamental conhecer o desenvolvimento cognitivo infantil e as habilidades necessárias no processo de leitura e construção de mapas. Por meio deste conhecimento é possível elaborar atividades para que as crianças leiam e interpretem as representações cartográficas. Desta maneira, pode-se evitar a elaboração de um produto que não seja compreendido e utilizado eficazmente pelo aluno. O estudo dos Parâmetros Curriculares Nacionais (BRASIL, 1998) possibilitou conhecer as diretrizes do ensino de Geografia, as quais viabilizaram o desenvolvimento do EDUCATLAS em módulos educacionais de aprendizagem. Vale ressaltar, como apontado por Voges et al. (2009), que a divisão de um Atlas Escolar em ciclos de aprendizagem pode favorecer a criação de um produto mais eficaz, eficiente e atrativo.

Nota-se que o uso de recursos de interatividade e animação no mapa de Recursos Minerais Brasileiros permitiu a criação de uma coleção de mapas. Com a utilização desses recursos pode-se adotar a variável visual estática matiz da cor para as classes, a qual possibilita o agrupamento instantâneo das categorias mais generalizadas, bem como aplicar esmaecimento e filtragem para criar coleção de mapas. De acordo com Martinelli (1991) a coleção de mapas é a solução ideal para se obter respostas visuais instantâneas de conjunto e respostas em nível elementar. Como trata-se de um mapa complexo, por conter divisão em três classes e grande quantidade de subclasses (24), a solução estática e exaustiva apresentada por Simielli (1988) pode dificultar a leitura eficiente de padrões espaciais. Recomendase, assim, que o mapa animado e interativo proposto seja comparado ao projeto original desenvolvido por Simielli (1988). Como Bochicchio (1995) aponta, os Atlas Escolares devem ter uma linguagem cartográfica simplificada, para que não cause prejuízo em seu conteúdo.

É importante ainda, apontar que a cartografia multimídia pode auxiliar a criança no desenvolvimento de suas habilidades processuais e de acesso (sintaxe), e assim, garantir que os Atlas Escolares sejam utilizados com eficiência no ensino de Geografia. Entretanto, há controvérsias quanto a eficácia da animação para educação. Morrison (2000) apud Slocum (2001) sugere que a animação para educação não é tão efetiva quanto os mapas estáticos. Embora, Slocum (2001) aponte que isto pode estar relacionado com diversos fatores, tais como método de representação e natureza do fenômeno geográfico. Além disso, Baulch et al., (2005) apontam que, enquanto estudos indicam que o desempenho dos estudantes é equivalente tanto para os métodos convencionais quanto para os métodos assistidos por computador, um corpo crescente na literatura sugere que os estudantes preferem os métodos assistidos por computador. Por outro lado, Slocum (2001) observa que há poucos estudos que tratam da interatividade, sendo que o foco está na animação. 
Sendo assim, recomenda-se que no futuro esse produto seja testado com um grupo de alunos do referido ciclo, para avaliar a real contribuição da animação e interatividade no ensino da Geografia, bem como a divisão do Atlas em ciclos de aprendizagem. Além disso, sugere-se que seja avaliado tanto no ensino fundamental privado quanto público, para que o desempenho possa ser comparado e, ainda, se o tipo de material didático adotado afeta significativamente os resultados.

\section{AGRADECIMENTOS}

Ao CNPq, à Faculdade de Ciências e Tecnologia da Universidade Estadual Paulista “Júlio de Mesquita Filho” (FCT/Unesp) e ao Programa de Pós-Graduação em Ciências cartográficas.

\section{REFERÊNCIAS BIBLIOGRÁFICAS}

BARROS, L. M. O. Desenvolvimento de um protótipo de Atlas Escolar Interativo. 152 f. Dissertação (mestrado em Ciências Cartográficas) - Faculdade de Ciências e Tecnologia, Universidade Estadual Paulista Júlio de Mesquita Filho, Presidente Prudente, 2007.

BARROS, L. M. O.; DECANINI, M. M. S. Desenvolvimento de um Atlas Escolar Interativo, Projeto e Produção. Boletim de Ciências Geodésicas, Curitiba, v.14, nº4, p.482-503, 2008.

BAULCH, S.; MACDONALD. R.; PULSIFER, P. L.; TAYLOR, D. R. F. Cybercartography: A Multimodal Approach. In: TAYLOR, F. Cybercartography: Theory and Practice. 5nd ed. Amsterdan - Tem Netherlands. p. 491-515, 2005.

BERTIN, J. Semiology of Graphics. Madison: The University of Wisconsin Press, 1983.

BOCHICCHIO, V. R. Atlas Atual Geografia: Manual de Cartografia. Editora Atual, 1995.

BOS, E. S. Cartographic Symbol Design. ITC. The Netherlands. 1984.

BRASIL. Parâmetros curriculares nacionais: geografia. Brasília: MEC/SEF, 1998.

BROWN, A.; EMMER, N.; VAN DEN WORM, J. Cartographic Design and Production in the Internet Era. The Cartographic Journal. v. 38, p. 61-72, The British Cartographic Society, 2001

CARSWELL, R. J. B.; DE LEEUW, G. J. A. Curriculum Relationship and Children`s atlases. Cartographica. Toronto: University of Toronto, California, v.24, n.1, p.135-145, spring. 1987.

CARTWRIGHT, W. Development of Multimidia. In: CARTWRIGTH, W.; PETERSON, M. P.; GARTNER, G. Multimedia cartography. 1.ed. New York: Springer, 1999, 343f.

CASTNER, H. W. Education through mapping. Cartographica. Toronto: University of Toronto, Califórnia, v.24, n.1 p.82-100, spring. 1987.

CRAMPTON, J. W. Interactivity types in geographic visualization. Cartography and geographic information science. N.29, v.2, p.85-98. 2002

Bol. Ciênc. Geod., sec. Artigos, Curitiba, v. 17, nº 4, p.496-518, out-dez, 2011. 
DECANINI, M. M. S.; IMAI, N. N. Mapeamento na Bacia do Alto Paraguai: Projeto e Produção Cartográfica. Revista Brasileira de Cartografia, 2000. p. 65-75.

DELAZARI, L. S. Modelagem e implementação de um atlas eletrônico interativo utilizando métodos de visualização cartográfica. Tese (Doutorado em Engenharia de Transportes) - Universidade de São Paulo, São Paulo, 2004.

DENT, B. D. Cartography Thematic Map Design. 3. ed WCB MCGraw-Hill, 1990. . Cartography Thematic Map Design. 5. ed WCB MCGraw-Hill, 1999.

GAMA, E. M.; BARBOSA, S. R. Geografia - Livro 1. In: C. Pitágoras, Ensino Fundamental - Oitava Série. Belo Horizonte: Del Rey. 2008.

KEATES, J. S. Cartographic design and production. e.2 New York: Longman Group, 1989.

KOLACNY, A. Cartographic Information - A Fundamental Concept and Term in Modern Cartography. Cartographica. Suplemento n.1, Vol. 14, p.39-45, 1977.

LIBEN, L. S.; KASTENS, K. M.; STEVENSON, L. M. Real-world knowledge through real-world maps: a developmental guide for navigating the educational terrain. Developmental Review. EUA. n. 22, p. 267 - 322. 2002.

MACEACHREN, A. M. How maps work: Representation, Visualization and Design. London: The Guilford Press, 1995

MARTINELLI, M. Analytic and synthesis maps on geographic school atlases. In: International Cartographic Conference Proceedings, Santiago: ICA/ACI, 2009

MARTINELLI, M. Curso de cartografia temática. ed. Contexto, 1991

PASSINI, E. Y. Alfabetização Cartográfica. São Paulo: Lê, 1995. 136p.

PIAGET, J. (1967). Elaboração do pensamento, intuição e operações. In: N. Campos, Psicologia da inteligência (E. Alencar, Trad., pp. 157-159). São Paulo: Fundo de Cultura SA.

SANTOS, F. P.; DECANINI, M. M. S. Projeto cartográfico de um Atlas Escolar Interativo para aluno do $4^{\circ}$ ciclo do ensino fundamental In: III SIMGEO Simpósio Brasileiro de Ciências Geodésicas e Tecnologias da Geoinformação, 2010, Recife. Anais do III Simpósio Brasileiro de Ciências Geodésicas e Tecnologias da Geoinformação. Recife, 2010.

SÃO PAULO. Proposta curricular do Estado de São Paulo: Geografia. Coord. Maria Inês Fini. - São Paulo: SEE, 2008

SCALZARETTO, R. Geografia. In: S. A. Ensino, Ensino Fundamenta - Oitavo ano. São Paulo: Editora Anglo. 2007.

SHNEIDERMAN, B. Designing the User Interface: Strategies for Effective HumanComputer Interaction. 3.ed. Addison-Wesley. 1998

SILVA, L, B, S, M. Elaboração do Atlas Geográfico Escolar de Mato Grosso. Colóquio de Cartografia Escolar. Juiz de Fora, 2009.

SIMIELLI, M. E. Geoatlas. São Paulo: Ática, 1988.

SLOCUM, T. A. Thematic cartography and visualization. Upper Saddle River: Prentice Hall, 2001. 
VOGES, M. et. al. Explorando o Google Earth e Atlas Eletrônico para ensino de Geografia: práticas em sala de aula. In: NOGUEIRA. R. E. Motivações hodiernas para ensinar geografia: Representação do espaço para visuais e invisuais. 1.ed. Florianópolis, 2009. p.81-103

(Recebido em junho de 2011. Aceito em outubro de 2011). 